\title{
Energy Use Efficiency of Different Drying Methods for Two Rough Rice Cultivars
}

\author{
Seyed Mehdi Nassiri", Seyed Mohammad Etesami \\ Department of Biosystems Engineering, Shiraz University, Iran
}

Copyright (C) 2015 by authors, all rights reserved. Authors agree that this article remain permanently open access under the terms of the Creative Commons Attribution License 4.0 International License

\begin{abstract}
In the present study two local cultivars of paddy (long and medium grain size) were dried in thin layer by three different methods included indirect active solar dryer, mixed-mode active solar dryer and continuous dryer, at three temperature levels of 35,45 , and $55^{\circ} \mathrm{C}$. Also, paddy was dried by sundry method as the traditional and common used method (control treatment). Energy consumption for different parts of aforementioned dryers was practically determined. Total drying energy per kilogram of dry mass of head rice yield (specific energy consumption) was calculated. Results indicated that medium size grains result more head rice yield than longer ones. No significant difference was observed for head rice yield form indirect and mixed-mode solar drying. Drying temperature significantly influenced on head rice yield and the specific energy consumption, so that the lowest ratio was obtained at $35^{\circ} \mathrm{C}$. Considering low specific energy consumption and drying time duration, continuous dryer acted more efficient than others.
\end{abstract}

Keywords Energy Consumption, Head Rice Yield, Paddy, Solar Dryer

\section{Introduction}

Rice is one of the main food sources in the world's people diet. According to the FAO reports, nearly 161 million hectares were under cultivation of rice with the total yield of 679 million tons in the world in year 2013, and ranked at second place after maize. It ranked after barley and wheat at third place in Iran [1].

Rough rice (paddy) needs to several processes from harvesting till supplying to the market in the form of white rice. The final quality of white rice is influenced by these processes. Drying as one of the main and of necessity processes has critical effect on the quality of final product. It was reported that paddy must be dried to moisture content about $13 \%$ w.b. for long storage. Also, for optimum head rice recovery in rice milling process the moisture content of paddy should be within the range of 10 to $13 \%$ w.b. [2, 3].
For some local paddy cultivars of Fars province, Iran, moisture content for milling process is recommended within the range of 8 to $10 \%$ w.b. $[4,5]$.

In general, drying is a critical operation in paddy process chain. The most losses of paddy during different post-harvest processes refer to the improper drying operation $[6,7,8]$. Thermal and moisture content gradients while drying produce stress within paddy kernels. The stress more than allowable limit, produces some cracks in kernels and reduces head rice recovery $[8,9,10,11]$

Drying is also important activity from economics point of view, because it is energy intensive process [6]. On the other hand, the price of a rice bulk containing the fissured kernels is reduced to one tenth of high quality rice, depending on the amount of cracked kernels [12]. The aim of the rice production industry is to produce whole kernel rice with low energy input and at the minimum possible time [13].

The main objective of the present study was to compare the head rice yield of two local paddy cultivars (medium and long size kernels) when paddy is dried by different drying methods. Assessing the specific energy consumption was another objective of the study.

\section{Materials and Methods}

\subsection{Samples}

Two local paddy cultivars Lenjan (medium-grain) and Fajr (long-grain) were collected from Fars Province, Iran. The initial moisture content for aforementioned cultivars was around 18 and $17 \%$ (w.b.), respectively. The samples were sealed in plastic bags and stored in a refrigerator at $4^{\circ} \mathrm{C}$. Samples were removed from the refrigerator 12 hours before drying to warm up at room temperature $\left(20^{\circ} \mathrm{C}\right)$. Moisture content was determined before and after each drying treatment by gravimetric method in an air-oven at $105^{\circ} \mathrm{C}$ for 24 hours [14].

Physical characteristics (length, width, thickness, slenderness, and the weight of 1000 kernels) of paddy and 
head rice of both cultivars were measured using a micrometer with an accuracy of $\pm 0.01 \mathrm{~mm}$. The measurements were performed for hundred kernels and the mean values were reported.

\subsection{Drying Systems}

The paddy samples were dried by different methods under certain conditions, however, final moisture content of $10 \pm 0.5$ w.b. was prepared for all samples.

\subsubsection{Continuous drying system with hot air}

A fabricated laboratory continuous dryer was used for drying.. Paddy was confined between two inclined screen sheets with $20 \mathrm{~mm}$ distance (thin layer drying as mentioned by Zomorodian \& Alameh, [15]). The heated air was passed through the paddy in transverse direction with flow rate of $0.28 \mathrm{kgm}^{-2} \mathrm{~s}^{-1}$. The air was heated up to three levels 35,45 and $55^{\circ} \mathrm{C}$. The temperature was controlled by PT- 100 sensor based thermostat. About $1600 \mathrm{~g}$ paddy fed into the dryer from upper hopper. The movement rate of paddy in dryer was controlled by a multi-vane rotary gate at the bottom of the dryer (Figure1). Discharged materials refilled into hopper manually.

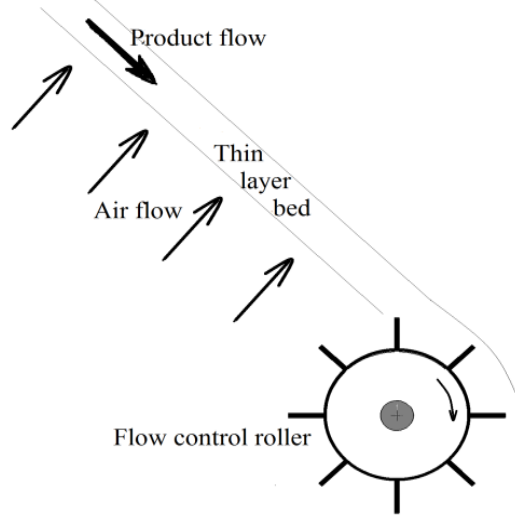

Figure 1. Schematic diagram of the continuous dryer

In each trial at first, 5, 15, 25 and 40 minutes from beginning, and afterward, each 20 minutes, the moisture content was measured by a portable moisture meter with the accuracy of $\pm 0.1 \%$.

\subsubsection{Indirect active solar drying system}

Dryer was equipped by a $1500 \times 550 \mathrm{~mm}$ flat solar collector. Collector was sloped about 45 degree [16]. Solar collector was covered by a black plastic sheet, so that three different temperature levels $\left(35,45\right.$ and $\left.55^{\circ} \mathrm{C}\right)$ were created. A 375 watt electrical heater was also used to help the solar collector for establishing a constant drying temperature at necessary times. The volumetric air flow rate was the same as previous tests $\left(0.28 \mathrm{kgm}^{-2} \mathrm{~s}^{-1}\right)$. About $1600 \mathrm{~g}$ paddy in 20 $\mathrm{mm}$ thickness spread over the dryer tray and inserted into the dryer. For determining the moisture content alternatively, the tray was weighed with a digital balance with the accuracy of $\pm 1 \mathrm{~g}$ at the periods same as previous tests (Figure 2).

\subsubsection{Mixed-mode active solar drying system}

The procedure was the same as indirect active solar dryer, except that the sun rays were also radiated directly to the filled sample tray.

\subsubsection{Sun drying}

This is a common method in paddy cultivation region of Fars province. Therefore, $3200 \mathrm{~g}$ paddy was evenly spread on concrete floor in $325 \times 225 \times 80 \mathrm{~mm}$ wooden boxes and exposed to the sun radiation. Samples were aerated manually for uniform drying every 2 hours. The samples were dried under sunny conditions with the average ambient temperature range between $25^{\circ} \mathrm{C}$ to $34^{\circ} \mathrm{C}$ and about $15.5 \%$ $\mathrm{RH}$.

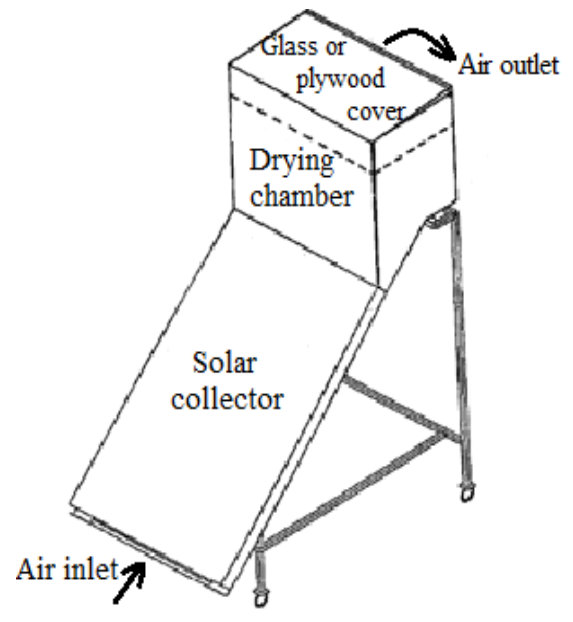

Figure 2. Schematic diagram of the solar dryer

\subsection{Tests Attribute Measurement}

In all above drying methods the amount of consumed energy was measured accordingly. The required energy for electric motor and blower set, heaters and any electrical consumers were measured by electricity counters. The solar energy was computed by considering the amount of average solar radiation (using shade meter) and surface area of the collectors.

Dried paddy samples were sealed in plastic bags and stored 24 hours at ambient temperature. The $50 \mathrm{~g}$ sub-samples were selected from each treatment and shelled using a laboratory scale rubber roller husker (model THU-35A, Satake, Japan). Brown rice was milled for $30 \mathrm{~s}$ in the Kett polisher (Kett electric laboratory, Tokyo, Japan) to remove the barns. Head rice yield (HRY) was calculated as the ratio of the mass of whole white rice kernels obtained to the total mass of paddy. The term "head rice" denotes white kernels with $3 / 4$ or more of the original kernel length $[17,18]$. The HRY was determined in three replicates.

Statistical analysis was conducted according to the factorial experiments based on completely randomized 
design. Experimental main factors were three kinds of dryers, and three air drying temperature levels. Analysis of variance (ANOVA) and Tukey post-test (at 5 percent level of significance) were applied for statistical analysis.

\section{Results and discussion}

\subsection{Morphological Properties}

Some physical characteristics of brown rice kernels have been showed in Table 1. As it is obvious, Fajr cultivar had more length and larger slenderness (length to width ratio) as compared to Lenjan.

Table 1. Some physical characteristics of Fajr and Lenjan (brown rice)

\begin{tabular}{ccccc}
\hline Cultivar & $\begin{array}{c}\text { Length } \\
(\mathrm{mm})\end{array}$ & $\begin{array}{c}\text { Width } \\
(\mathrm{mm})\end{array}$ & $\begin{array}{c}\text { Thickness } \\
(\mathrm{mm})\end{array}$ & Slenderness \\
\hline Fajr & $7.3 \pm 0.2^{\mathrm{a}}$ & $1.9 \pm 0.1^{\mathrm{a}}$ & $1.8 \pm 0.1^{\mathrm{a}}$ & $3.8 \pm 0.2^{\mathrm{a}}$ \\
Lenjan & $6.0 \pm 0.4^{\mathrm{b}}$ & $2.3 \pm 0.2^{\mathrm{b}}$ & $1.7 \pm 0.1^{\mathrm{a}}$ & $2.7 \pm 0.3^{\mathrm{b}}$
\end{tabular}

The same letters in each column are not significantly different $(\mathrm{P}<0.05)$ mean \pm standard deviation

\subsection{Head Rice Yield}

The amount of HRY was obtained after whitening. Analysis of variance on HRY values showed that the cultivar, drying air temperature and drying method and their interctions significantly influenced the HRY $(\mathrm{P}<0.05)$. Medium-grain cultivar, Lenjan, had more HRY than Fajr as long-grain cultivar. This is mainly due to the texture of two cultivars and variation in environmental conditions while growing the plants as well as the slenderness ratio of kernels. It was reported that ambient temperature during grain development especially in the grain filling stage plays a vital role for unexplained fluctuations in rice grain quality $[19,20]$. Longer kernels did not tolerate against the developed forces while dehusking and whitening. The same results was observed in Mathews and Spadaro [21], and clement and Seguy [22] reports.

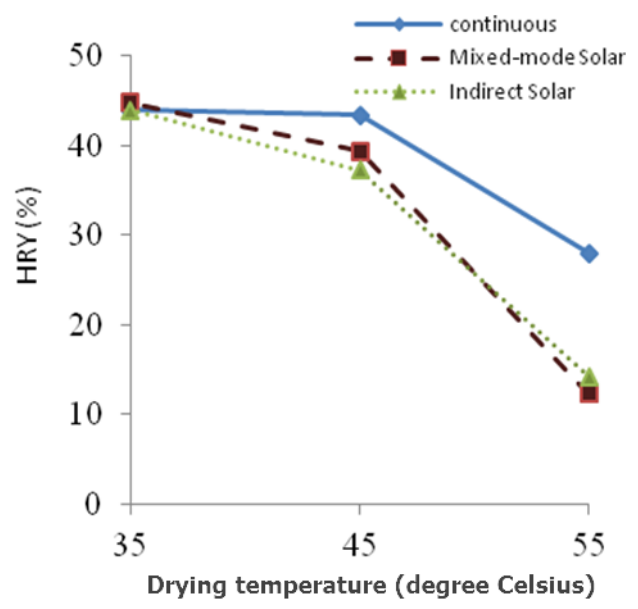

Figure 3. Interaction effect of drying air temperature and drying method on HRY
The HRY losses were increased by increasing in drying air temperature from 35 to $55^{\circ} \mathrm{C}$. At the higher drying temperatures cracks were developed in kernels by created thermal stresses [12, 23, 24], and thereby HRY was reduced as shown in Figure 3. Continuous drying at higher temperature improved the amount of HRY as compared to indirect and mixed-type solar drying; while results showed insignificant difference between indirect and mixed-mode active solar drying methods.

The HRY was not influenced by direct solar radiation in mixed-type solar dryer. Heating and tempering periods in the continuous drying method led to safeguard the rice kernels while drying and to raise HRY. As reported by Renjie et al. [25] tempering had significant influences on the moisture content gradient in kernels and remove moisture stress from grain.

The most HRY was obtained when paddy was dried at $35^{\circ} \mathrm{C}$ in all drying methods. Also, drying method had no effect on HRY loss at lower drying temperature (Figure 4). At higher temperature non-uniform and rapid drying process produced more broken. If fast rate drying is desired, continuous dryer is more suitable. It is due to this fact that drying air contacts with grains in better manner when they are moved. On the other hand, there is a short tempering period between discharging from dryer and reloading. Hence, this period decreases thermal stresses in kernels.

\subsection{Energy Use Efficiency}

The amount of total energy use per kilogram of vaporized water was calculated as an index of energy use efficiency (Figure 5). The ratio was from 9.1 to $57.5 \mathrm{MJ} / \mathrm{kg}$ of vaporized water. The minimum and maximum values were obtained for continuous dryer at $35^{\circ} \mathrm{C}$ and indirect solar dryer at $45^{\circ} \mathrm{C}$, respectively. Lower ratio at $35^{\circ} \mathrm{C}$ referred to minimum energy consumption to heat up the ambient air temperature (on average $28^{\circ} \mathrm{C}$ ) in one hand, and adequate time for moisture emission inside the kernel on the other hand. At $55^{\circ} \mathrm{C}$ the phenomenon was quite different.

High temperature produced more water vapor pressure inside the kernels and pushed out the moisture. Though, more energy was applied for drying, but the amount of removed water was also more. This can be due to exponentially increase in the diffusion coefficient of paddy at the higher temperatures [26]. Therefore, this ratio decreased as compared to corresponding value at $45^{\circ} \mathrm{C}$. It should be recalled that drying at $55^{\circ} \mathrm{C}$ produced more fissured kernels because of thermal stresses. Weerachet et al. [27] reported that this ratio was 3.9 to $4.4 \mathrm{MJ} \mathrm{kg}^{-1}$ of vaporized water. The difference might refer to the method of drying in the present study in thin layer form. It is evidence that most of heated air has been vented out from dryer without effective use and recovery.

The ratio of total energy consumption per kilogram of dry matter of head white rice (specific energy consumption) was calculated for different drying methods. The lowest ratio was for continuous drying at $35^{\circ} \mathrm{C}$ and the highest was for 
solar dryer at $55^{\circ} \mathrm{C}$. It is clear that continuous drying method was the best method because of low energy consumption and uniform drying (Figure 6). It is important to know that on average nearly $67 \%$ of energy use by solar dryers was prepared by sun radiation. Consequently, the ratio of electrical energy use per kilogram of dry matter of the head rice was calculated as tabulated in Table 2. Results revealed a reciprocal relation for specific energy consumption.
Drying duration as another index was also taken in to the account (Table 3). It seems that paddy has stayed longer time in continuous dryer than other dryers, but by considering the required rest times for discharging and refilling the dryer, it can be concluded that this dryer acted more efficient than others.
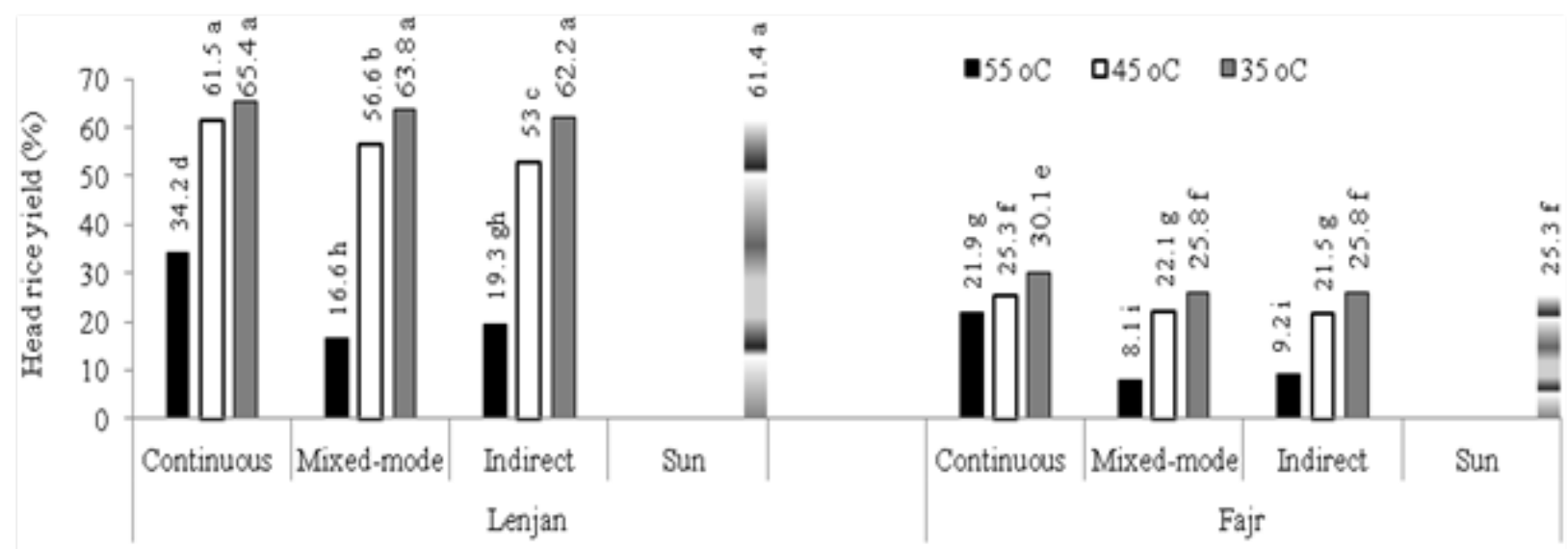

Dryingmethod

The same lower case letters are not significantly different $(\mathrm{P}<0.05)$.

Figure 4. Percentage of head rice yield in all experiment treatments.

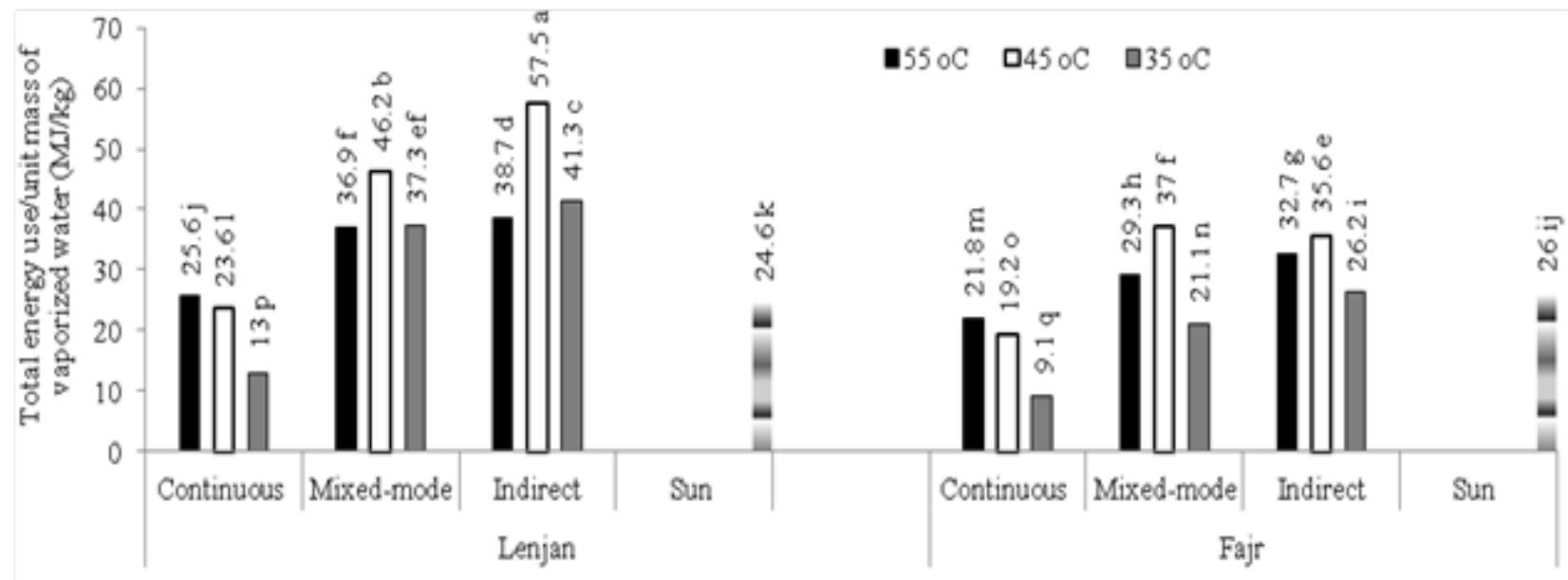

Dryingmethod

The same lower case letters are not significantly different $(\mathrm{P}<0.05)$.

Figure 5. Total energy use per unit mass of vaporized water in all experiment treatments. 


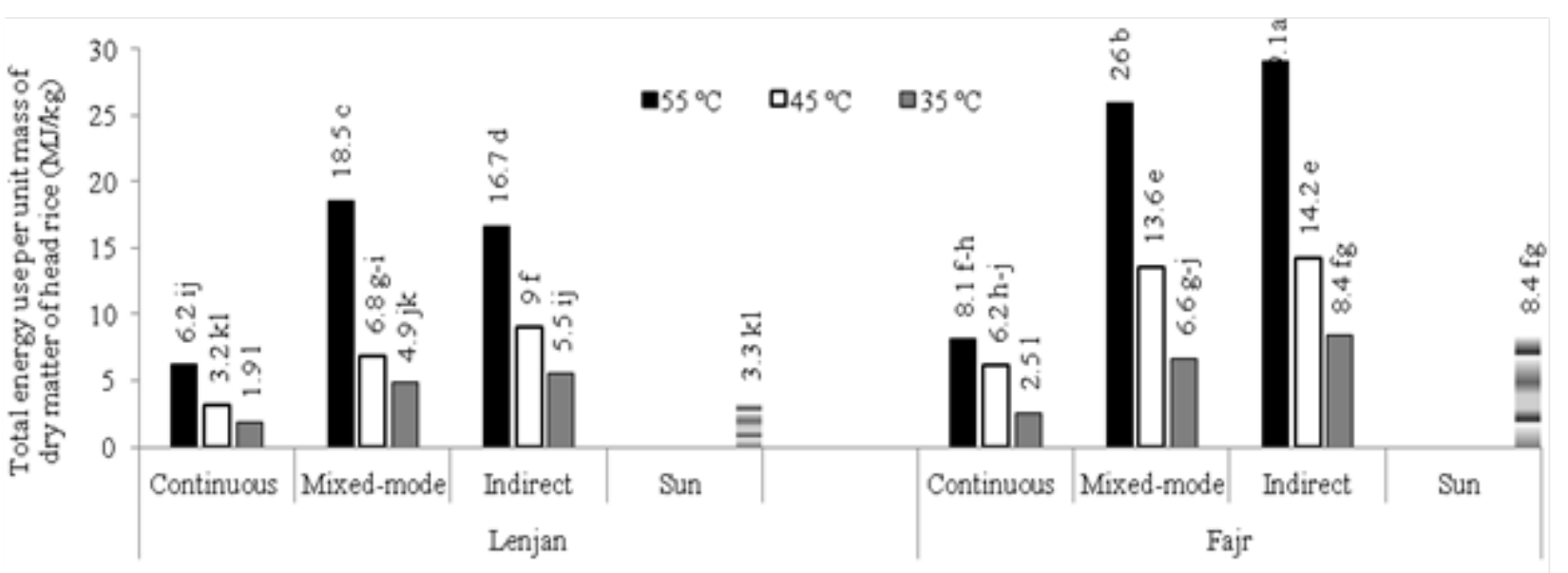

Dryingmrthod

The same lower case letters are not significantly different $(\mathrm{P}<0.05)$.

Figure 6. Total energy use per unit mass of dry mater of head rice in all experiment treatments.

By considering drying time, drying at 35 degree Celsius consumed more electrical energy for producing a unit of HRY (Table 2). Though drying at lower drying temperature resulted higher HRY [28, 29, 30, 31], but it consumes more electrical energy due to higher drying duration. Therefore, a tread off should be made while drying.

Table 2. Ratio of electrical energy use to unit of dry matter of head rice $\left(\mathrm{MJkg}^{-1}\right)$ by solar dryers

\begin{tabular}{ccccc}
\hline \multirow{2}{*}{$\begin{array}{c}\text { Paddy } \\
\text { Cultivar }\end{array}$} & Drying & \multicolumn{3}{c}{ Drying Temperature $\left({ }^{\circ} \mathrm{C}\right)$} \\
\cline { 3 - 5 } & Method & 35 & 45 & 55 \\
\hline \multirow{2}{*}{ Lenjan } & Mix. Solar & 6.7 & 2.1 & 1.6 \\
& Ind. Solar & 6.2 & 2.7 & 2.1 \\
\hline \multirow{2}{*}{ Fajr } & Mix. Solar & 9.9 & 3.9 & 2.2 \\
& Ind. Solar & 10.7 & 4 & 3.7 \\
\hline
\end{tabular}

Mix. and Ind. refer to mixed and indirect solar dryer

Table 3. Drying time (min) for different drying methods

\begin{tabular}{ccccc}
\hline \multirow{2}{*}{$\begin{array}{c}\text { Paddy } \\
\text { Cultivar }\end{array}$} & Drying & \multicolumn{3}{c}{ Drying Temperature $\left({ }^{\circ} \mathrm{C}\right)$} \\
\cline { 3 - 5 } & Method & 35 & 45 & 55 \\
\hline \multirow{4}{*}{ Lenjan } & Continuous & 368 & 262 & 150 \\
& Mix. Solar & 306 & 141 & 70 \\
& Ind. Solar & 339 & 179 & 76 \\
& Sun & & $669^{*}$ & \\
\hline \multirow{3}{*}{ Fajr } & Continuous & 247 & 173 & 123 \\
& Mix. Solar & 175 & 115 & 56 \\
& Ind. Solar & 227 & 111 & 56 \\
& Sun & & $709^{*}$ & \\
\hline
\end{tabular}

Mix. and Ind. refer to mixed and indirect solar dryer

* In ambient temperature (with mean of $29.5^{\circ} \mathrm{C}$ )

\section{Conclusions}

The study showed that:
- Medium length grains had more HRY than longer one.

- HRY was improved when paddy was dried by continuous dryer.

- There was no significant difference between HRY for indirect and mixed-type solar dryer.

- There was an inverse relationship between drying air temperature and HRY.

- The highest ratio of total energy use per kilogram of dry mass of head rice was obtained at $55^{\circ} \mathrm{C}$. But in electrical form, lower ratio was observed at same temperature. Consequently, drying temperature should be selected by comprising between specific energy consumption and maximum HRY.

- Combination of solar collectors and continuous dryer can be recommended for drying paddy for maximum HRY, minimum electrical energy consumption, and therefore minimum ratio of specific energy consumption.

\section{REFERENCES}

[1] Anonymous. 2015. Food and agriculture organization of the United Nations (FAO). Available at:

http://faostat/fao/org/site/567/DesktopDefault/aspx?PageID= 567.

[2] N. Teter, Paddy Drying Manual-Food and Nutrition Series, FAO Publication, Italy, 1987.

[3] Y. Tirawanichakul, Prachayawarakorn, S., Varanyanond, W., and Soponronnarit, S. "Simulation and grain quality for in-store drying of paddy". Journal of Food Engineering, (2004) 64: 405-415.

[4] M. Shaker, Alizadeh, M. R. "Evaluation and determination of the most proper of kamfiruzi paddy moisture content range for decrease of rice breakage". Proceedings of the $8^{\text {th }}$ National 
Seminar on Rice, Karaj, Iran,(2002). (In Persian).

[5] N. Sadeghi, Nassiri, S. M. "The effect of paddy moisture content on milling losses and post-milling crack development in rice kernel under different storage conditions". XVII ${ }^{\text {th }}$ World Congress of the International Commission of Agricultural Engineering (CIGR), Canada. (2010).

[6] F. W. Brooker, Bakker-Arkema, D. B. and Hall, C. W. "Drying and Storage of Grains and Oilseeds". AVI Pub. Company, USA, (1992).

[7] A. G. Cnossen, Siebenmorgen, T. J. "The glass transition temperature concept in rice drying and tempering effect on milling quality". Transaction of the ASAE, (2000) 23:16611667.

[8] S. Prachayawarakorn, Poomsaad, N. and Soponronnarit, S. "Quality maintenance and, economy with high-temperature paddy-drying processes". Journal of Stored Production Research. (2005) 41(3): 333-351.

[9] W. Yang, Jia, C. Siebenmorgen, T. J. Howell, T. A. and Cnossen, A. G. "Intra-kernel rice moisture responses to drying and tempering treatments by finite element simulation". Transactions of the ASAE. (2002) 45: 10371044.

[10] T. J. Siebenmorgen, and Qin, G. "Influence of drying on rice fissure formation and mechanical strength distributions". Transactions of the ASAE, (2005) 48 (5): 1835-1841.

[11] Q. Zhang, Yang, W. and Sun, Z. "Mechanical properties of sound and fissured rice kernels and their implications for rice breakage". Journal of Food Engineering, (2005) 68: 65-67.

[12] F. Courtois, Abud-Archila, M. Bonazzi, C. Meot, J. M. and Trystram, G. "Modeling and control of a mixed flow rice dryer with emphasis on breakage quality". Journal of Food Engineering, (2001) 49(4): 303-309.

[13] N. N. Sarker, Kunze, O. R. and Strouboulis, T. "Transient moisture gradients rough rice mapped with finite element model and related to fissure after heated air drying". Transactions of the ASAE, (1996) 39(2): 625-631.

[14] AOAC. Official methods of analysis, 12th edition, Association of Official Analytical Chemists, Washington DC. USA, (1985).

[15] A. Zomorodian, and Allameh, A. R. "Evaluation of thin layer drying process for paddies and determining appropriate grain thin layer depth using a natural convection pilot solar dryer". Journal of Water and Soil Science, (2003) 6 (4): 209-218. (In Persian)

[16] J. A. Duffie, and Beckman, W.A. "Solar Engineering of Thermal Processes", 2nd edition, John Wiley and Sons, Inc., New York, USA, (1991).

[17] J. Aquerreta, Iguaz, A. Arroqui, C. and Virseda, P. "Effect of high temperature intermittent drying and tempering on rough rice quality". Journal of Food Engineering, (2007) 80: 611618.

[18] B. K. Yadav, and Jindal, V. K. "Changes in head rice yield and whiteness during milling of rough rice (Oryza sativa L.)". Journal of Food Engineering, (2008) 86: 113-121.

[19] S. Peng, Huang, J. Sheehy, J. Laza, R. C. Visperas, R. M. Zhong, X. Centeno, G. S. Hkush, G. S. and Cassman, K. G. "Rice yields decline with higher night temperature from global warming". Proceeding of the National Academy of Sciences of the United States of America, (2004) 101: 9971-9975.

[20] N. T. W. Cooper, Siebenmorgen, T. J. Counce, P. A. and Meullenet, J.F. "Explaining rice milling quality variation using a historical weather data analysis". Cereal Chemistry, (2006) 83: 447-450.

[21] J. Mathews, and Spadaro, J. J. "Breakage of long grain rice in relation to kernel thickness". Cereal Chemistry. In: Rice Production and Utilization. AVI Publishing Co. INC., USA, (1976).

[22] G. Clement, Seguy, J. "Behavior of rice during processing". Agricultural Development, (1994) 3: 38-46.

[23] A. Iguaz, Rodriguez, M. and Virseda, P. "Influence of handling and processing of rough rice on fissures and head rice yields". Journal of Food Engineering, (2006) 77: 803809.

[24] A. M. Kermani, Tavakoli-Hashjin, T. and Khoshtaghaza, M. H. "Investigation about capability of crack formation due to stress for two varieties of rice (Hashemi and Khazar) under thin-layer drying process paddy". Agricultural Science, (2006) 37(4): 697-700.

[25] D. Renjie, Zhanhui, L. Zhuqing, L. Shoji, K. and Wei, C. "Effect of drying and tempering on rice fissuring analyzed by integrating intra-kernel moisture distribution". Journal of Food Engineering, (2010) 97: 161-167.

[26] N. Poomsaad, Soponronnarit, S. and Therdyotin, A. "Diffusion model of paddy drying by fluidization technique". In: Proceedings of the 14th Memorial CIGR World Congress, Japan, (2000).

[27] J. Weerachet, Saeteaw, N. and Charoenchaisri, A. "Industrial paddy drying and energy saving options". Journal of Stored Products Research, (2010) 46: 209-213.

[28] J. Hashemi, Ashraful Haque, M. Shimizu, N. and Kimura. T. "Influence of drying and post-drying conditions on the head rice yield of aromatic rice". Agricultural Engineering International: the CIGR Ejournal. Vol. X. (2008).

[29] Z. Mehdizadeh, and Zomorodian. A. "A study of the effect of solar drying system on rice quality". Journal of Agricultural Science and Technology, (2009) 11: 527-534.

[30] J. O. Akowuah, Addo, A. and Bart-Plange. A. "Influence of drying temperature and storage duration on fissuring and milling quality of jasmine 85 rice variety". Journal of Science and Technology, (2012) 32(2): 26-33.

[31] N. Salehi Babamiri, and Askari Asli-Ardeh. E. "Effect of drying temperature and final grain moisture content on the hulling and head rice yield efficiency of some common rough rice varieties". International Journal of Agriculture and Crop Sciences, (2013) 6(9): 529-533. 